\title{
Lateral Rectus Palsy: Complication Following Opiate Pump Placement
}

\author{
Robert E. Windsor, MD, and Samuel Thampi, MD
}

This case report is of a 46 -year-old patient who developed blurred vision shortly following an opiate pump (Drug Administration System, DAS) placement for chronic pain due to chronic lumbar radiculopathy and a multiply operated spine. Following the im-

\section{CASe Report}

A 46-year-old female sustained a work related back injury leading to a laminectomy and discectomy in 1997 and subsequently a posterior instrumented fusion in 1999. She continued to have severe recalcitrant pain and was deemed not to be a candidate for further surgical intervention by her surgeon. She was referred to our clinic for pain management in 2001.

Physical therapy, epidural cortisone injection, medial branch block, bracing and trigger point injections failed to improve her pain. Oral medications were ineffective, as doses required to control her pain caused intolerable side effects. Psychometric testing was within normal limits except for situational depression. She responded well to an intrathecal injection of morphine sulfate. As a result, an intrathecal pump was implanted in March 2002.

\section{Surgical Technique}

The patient was positioned in the left lateral decubitus position and sterilely prepped and draped. Appropriate conscious sedation and preemptive analgesia with $0.5 \%$ bupivacaine with epinephrine was used as appropriate throughout the procedure. A 3 inch epidural needle was

From Georgia Pain Physicians, Marietta, Georgia. Address Correspondence: Robert E. Windsor, MD, Georgia Pain Physicians, 2550 Windy Hill Rd. Suite 215, Marietta, GA-30067

E-mail:rwindsor@aol.com

Funding: There was no external funding in preparation of this manuscript.

Conflict of Interest: None plant she complained of positional headaches and blurred vision. The headache gradually subsided with rehydration. However, one week after the pump placement she continued to complain of blurred vision and diplopia. Neurologic examination re-

advanced into the thecal sac at L2-3 under fluoroscopic guidance. Intrathecal access was identified by a wet tap and confirmed by the injection of a small amount of non-ionic contrast agent radiographically demonstrating a myelographic pattern. A Medtronic intrathecal catheter was advanced up the intrathecal space to the T9 vertebral level. A $4 \mathrm{~cm}$ right paramedian incision was made and carried down to the supraspinous ligament. A purse string suture was placed in the soft tissues surrounding the epidural needle at the level of the supraspinous ligament and snugly tightened. The needle was removed using a push-pull technique and the catheter remained in place. The stylet was removed from the catheter and the catheter remained patent as CSF was seen to drip from the catheter tip. The catheter tip was crimped to block further leakage from the catheter. The paramedian incision was packed off and attention was turned to creating the pocket.

After an appropriate field block, an 8-10 cm horizontal incision was made in the right lower quadrant of the abdomen taking the incision down into the subcutaneous fat, $2-3 \mathrm{~cm}$ deep to the skin. Using a combination of blunt and sharp dissection, a $10 \mathrm{~cm} \mathrm{x} 10 \mathrm{~cm}$ subcutaneous pocket was created. After packing the pocket, a tunneling rod was advanced from the paramedian incision to the superolateral corner of the pocket. The intrathecal catheter was fed through the tunneling tube and the tunneling tube was pulled through the tunnel and out of the pocket. The distal tip of the catheter was ex- vealed left lateral rectus palsy. A neurologist was consulted who confirmed the diagnosis. The symptoms gradually abated.

Keywords: Lateral rectus palsy, opiate pump, Drug Administration System, headache, failed back surgery.

cised leaving approximately $17-18 \mathrm{~cm}$ of catheter remaining outside the pocket side of the tunnel. The sterile water packaging in the pump reservoir was aspirated and it was replaced with $100 \mathrm{mg}$ of morphine sulphate in $10 \mathrm{ml}$. The catheter tip was ligated to a Medtronic SynchroMed pump inlet using the Medtronic connecting pin and sleeve. Both the paramedian incision and the pocket were irrigated with a Bacitracin solution. The paramedian incision was closed using a two-layer closure and subcuticular stitches with absorbable suture. The pocket was checked for bleeders and found to be "dry." The pump was placed in the caudal end of the pocket and a two-layer closure was performed, with absorbable suture. The patient was transferred to the recovery area in good condition. The pump was initially programmed to deliver $1.5 \mathrm{mg}$ of morphine sulfate per day on a continuous flow basis. The patient was discharged to home the same day with instructions to remain in bed for three days except for bathroom privileges.

\section{Post-operative Follow Up}

The day following the implant the patient called into the office complaining of a positional headache. A prescription of butalbital with codeine was provided and she was reminded to stay flat in bed as much as possible and drink non-caffeinated beverages. The patient returned to the clinic for follow up in 5 days as instructed. Her bandages were dry and her surgical sites looked clean and healthy. By that time her headache had resolved, how- 
ever she complained of blurred and double vision. Initially, it was thought to be due to a constitutional reaction to the morphine so her daily dose was reduced to $0.75 \mathrm{mg}$ per day. She was instructed to return to our clinic in two days. Upon return her symptoms had not improved so her pump flow rate was returned to $1.5 \mathrm{mg}$ per day and a detailed neurological exam was performed. She was determined to have an isolated left lateral rectus palsy as her only apparent neurological deficit was that her left eye remained in the midline while her right eye medially deviated as she was asked to gaze to the left. She was referred to a neurologist who confirmed the diagnosis. A brain MRI was performed which was determined by a neuroradiologist and the neurologist to be within normal limits. The neurologist recommended a course of expectant observation. He suggested that the lesion was temporary and would resolve on its own in the coming weeks. Within two weeks of seeing the neurologist her vision had returned to normal.

\section{DISCUSSION}

Intrathecal access during opiatepump catheter placement can cause prolonged cerebrospinal fluid leakage and delayed closure of a dural defect causing intracranial hypotension. Downward "sagging" of the brain and traction on cranial nerves may lead to Abducens nerve palsy. Lateral rectus palsy following lumbar puncture has been reported in the literature when using a large gauge needle $(1,2,3)$ Following an exhaustive search, the authors feel confident that this is the first report of a case of lateral rectus palsy following the placement of a Drug Administration System (DAS).

The Abducens nerve (VI cranial nerve) takes a long route from its origin in the Pons and passes through the superior orbital fissure to the lateral rectus muscle. The nerve arises on the ventral aspect of the pontomedullary junction and ascends on the basilar part of the occipital bone. It then runs anterolaterally in the pontine cistern after which it enters the cavernous sinus where it lies lateral to the Internal Carotid Artery. The nerve passes through the medial portion of the superior orbital fissure to enter the orbit to innervate the Lateral Rectus muscle (4-6). The nerve is vulnerable to compressive or other lesions at multiple sites. The following table illustrates the causes of lateral rectus palsy at various locations (Table 1$)(7,8)$.

The presented case emphasizes the need to recognize diplopia after DAS placement, as intrathecal access with subsequent CSF loss may cause the syndrome.

\section{CONCLUSION}

Lateral Rectus palsy is a potential complication of DAS placement. Knowledge and recognition of this syndrome is important in patients who present with diplopia following DAS placement. As it is rare, other causes of lateral rectus palsy must be ruled out. As in this case, most cases of lateral rectus palsy resolve spontaneously however, it is important to differentiate a case that is likely to resolve from one that may require additional, proactive treatment.

Table 1. Causes of sixth Nerve Palsy at various locations

\section{Lesion of the Abducens nerve fibers as they sweep forward and descend within the pons:}

- Infection- Viral infections involving the pons

- Infarction- Brain stem stroke

- Malignancies- infiltrative glioma involving pons

- Demyelinating disorders-Multiple sclerosis

- Other causes- Wernicke's encephalopathy (multiple small hemorrhages)

\section{Lesion of the Abducens nerve fibers as they leave the Pons and enter the Cavernous sinus}

- Traumatic -fractures of the base of the skull.

- Aneurysm of the Basilar artery or anterior inferior cerebellar artery.

Lesions of the Abducens nerve at the cavernous sinus. Here lesions may also involve the $3^{\text {rd }}, 4^{\text {th }}$ and the first division ( $V_{1}$ ophthalmic nerve) of the trigeminal nerve.

- Aneurysm of the internal carotid artery.

- Carotid-Cavernous fistula

- Cavernous sinus thrombosis.

\section{Lesions of the sixth nerve at the superior orbital Fissure}

Inflammation- Inflammation of the petrous bone and its dura due to secondary middle ear infections. Granuloma formation e.g. Tolosa-Hunt Syndrome

\section{Other causes can be:}

- Raised intracranial pressure.

- Lesion of the overlying temporal lobe e.g. tumor

- Head trauma

Lesions at the Abducens nerve nucleus

Congenital underdevelopment of the nucleus. 


\section{Author Affiliation:}

Robert E. Windsor, MD

Program Director, Emory

Georgia Pain Physicians Pain

Management Fellowship

President, Georgia Pain Physicians, PC

Associate Clinical Professor, Emory

Department of Physical Medicine \&

Rehabilitation

2550 Windy Hill Rd., Suite 215

Marietta, GA 30067

E-mail: rwindsor@aol.com

Samuel Thampi, MD

Associate Clinical Professor, Emory

Department of Physical Medicine \&

Rehabilitation

2550 Windy Hill Rd., Suite 215

Marietta, GA 30067

\section{REFERENCES}

1. Niedermuller U, Trinka E, Bauer G. Abducens palsy after lumbar puncture. Clin Neurol Neurosurg 2002; 104: 61-63.

2. Thomke F, Mika-Gruttner A, Visbeck $A$ et al. The risk of abducens palsy after diag. nostic lumbar puncture. Neurology 2000; 854:768-769.

3. Victor M, Ropper AH. Disorders of ocular motion and papillary function. In Victor M, Ropper AH (eds). Principles of Neurology, $7^{\text {th }}$ Edition. McGraw-Hill Medical Publishing Division, New York, 2001:286-287.

4. Moore KL. Cranial Nerves. In Moore KL (ed). Clinically Oriented Anatomy, $3^{\text {rd }}$ edition. Williams \& Wilkins, Baltimore, 1992: 853-875.
5. Barr ML. Brain stem: External anatomy. In Barr ML (ed). The Human Nervous System, $3^{\text {rd }}$ edition. Harper and Row, Hagerstown, 1979:71.

6. Snell RS, Lemp MA. The orbital nerves. In Snell RS, Lemp MA (eds). Clinical Anatomy of the Eye. Blackwell Science Publications, Boston, 1989:274-276.

7. Snell RS, Lemp MA. The orbital nerves. In Snell RS, Lemp MA (eds). Clinical Anatomy of the Eye. Blackwell Science Publications, Boston, 1989:279-280.

8. Victor M, Ropper AH. Disorders of ocular motion and papillary function. In Victor M, Ropper AH (eds). Principles of Neurology, $7^{\text {th }}$ Edition. McGraw-Hill Medical Publishing Division, New York, 2001: 282-285. 
